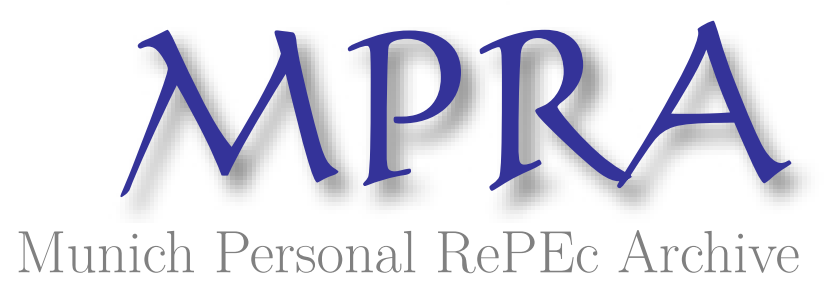

\title{
Impact of financial education and transparency on borrowing decisions. the case of consumer credit
}

Caratelli, Massimo and Ornella, Ricci

January 2011

Online at https://mpra.ub.uni-muenchen.de/37112/

MPRA Paper No. 37112, posted 05 Mar 2012 12:37 UTC 


\title{
Impact of Financial Education and Transparency on Borrowing Decisions. The Case of Consumer Credit
}

\author{
Massimo Caratelli \\ Department of Managment and Law \\ University of Roma Tre \\ ma.caratelli@uniroma3.it \\ Ornella Ricci \\ Department of Managment and Law \\ University of Roma Tre \\ ma.caratelli@uniroma3.it
}

working paper, January 2011

\begin{abstract}
Existing studies are not conclusive in favor of a strong relationship between the financial literacy and the ability to take better borrowing decisions. Results are quite heterogeneous and often point out the relevance of other factors, such as socio-demographic features or practical experience gained with daily use of financial products. The impact of (the amount and quality of) information available at the time of consumer choice is still unexplored. The objective of this paper is to fill in this literature gap and explore a large set of possible drivers of borrowing decisions in the consumer finance framework, with a specific focus on the transparency of price conditions.

We interviewed a sample of 299 consumers. They were asked to select the best option between five series of credit alternatives. In order to explore the role of transparency, each series of loans was presented with three different sets of information, with an increasing level of detail. The ability to select the best alternative was measured calculating a score based on the Net Present Value criterion, and analysed as the dependent variable of a regression model with demographic, socioeconomic and financial characteristics as predictors.

Our findings show that the amount and quality of available information strongly influence the choice. At the same time, an high level of education do not seem to play a significant role. Financial maturity results to positive influence the ability to select the best alternative and employed people perform better than non-working respondents.
\end{abstract}

JEL classification: G21, G28, D82, I22

Keywords: Financial education, Transparency, Borrowing, Consumer credit, Decision making

\section{Introduction}

The recent global financial crisis has drawn the attention of both scholars and supervisory authorities to the issue of financial education in the hope that it might contribute to the development of more efficient markets. What we mean by financial education is the series of measures designed to educate those who are to take responsible decisions regarding the use and management of their money (Noctor et al., 1992). These measures address the area of individual knowledge, capability and personality and deal with such themes as credit, investment processes and planning. While the addressees are usually high school or university students, there are also proposals that are targeted at the adult population.

A few countries, firstly among them the United States, the United Kingdom and Australia, have already implemented a number of financial education initiatives starting from the early 2000. At the same time, those countries have conducted surveys with a view to evaluating the effectiveness of the programs that had been carried out. Despite the considerable efforts and the number of analyses, their outcome is still uncertain. Various scholars have accounted for the poor effectiveness of the surveys by referring to the gaps in household finance - a still evolving research field that lacks shared evaluation standards and 
consolidated trends -, the difficulties in constructing data sets that are representative of individual choices, the long time required to cause the precepts to be metabolized by participants and translated into better decisions.

In spite of the poor findings, the financial education initiatives arouse considerable enthusiasm and entail the allocation of massive investments, not infrequently taken away from the development of alternative consumer protection tools, such as the transparency of the contractual terms and conditions.

This paper reviews the determinants of the borrowing choices with a view to offering policymakers guidance in the adoption of effective tools to protect the users of financial services. The research context is confined to consumer credit. A significant impact of study curricula on the quality of decisions would warrant a bias for financial education initiatives addressing primarily the younger population, while transparency reasons would warrant a marked involvement in the decision making process of the information available upon subscription. The support, if any, of work experience or practice in the use of financial services would promote alternative tools, such as tax incentives on labor and investments, or financial education programs addressing primarily grown-ups. While the incentives are likely to produce effects in the short run, the programs of financial education would prove effective if they were to spread their precepts through word-of-mouth and social networks. The benefits from the latter initiatives could be reaped in the longer run, as they are likely to require more than one generation to show up.

The rest of the paper is organized as follows: section 2 presents a review of the financial education literature; section 3 describes the empirical analysis and section 4 comments on its results. At the end, section 5 shows the implications of the analysis, as well as the limits and the likely developments of this survey.

\section{Literature review}

The overall picture of the studies on financial education has been broken down in such a way as to deal with the following topics: the two research currents into which the applications can be divided; the methods and the explanatory variables that have been adopted; and the limits of the investigations that have been carried out. A short reference to the studies dealing with the criteria for selecting the financial products that are likely to make up for some of the gaps that have been found is attached to the end of the section.

As regards the two research currents, the first one comprises the applications that ascertain the level of financial education of specific populations and of the socio-demographic groups that make them up. Special attention has been devoted to the most disadvantaged classes and immigrants. The major analyses concern the United States, the United Kingdom and Australia. Quite often, the studies entail large-scale sample surveys promoted by government bodies, supervisory authorities, and leading private banks. Since 1946, the University of Michigan has organized a monthly survey of 500 households, interviewed by telephone throughout the territory of the United States, with a view to documenting changes in consumer attitudes and expectations with regard to finance decisions. The Federal Reserve Board (FRB) commissioned, for the surveys of November and December 2001, 28 additional questions (in the form of "true or false" quizzes) regarding the financial literacy of the household. The FRB survey also asked consumers to outline the level of diffusion of 18 different financial management behaviors (ranging from tracking expenses to investment diversification) and their experience with 13 different financial products (from current accounts to pension plans). The resulting picture is by no means encouraging: the 1,004 respondents (all over 18 years of age) answered correctly to little more than $60 \%$ of the questions, with a better performance in the credit area ( $81 \%$ correct answers) and a worse performance in the investment area (52\%). As for their financial practices, $89 \%$ of the respondents had a checking account; $46 \%$ kept track of their expenses; $45 \%$ had recourse to company pension plans; $24 \%$ invested in stock, while only $6 \%$ invested in bonds. These results are in line with those reported in more recent studies conducted in the United States (Lusardi and Mitchell, 2007).

In 2005, the Financial Services Authority (FSA) commissioned a survey to measure 
the financial capability of the British citizens. The study involved 5,328 individuals over 18 years of age throughout the United Kingdom. Each participant was submitted to a face-to-face interview. The survey had recourse to a questionnaire with over 250 questions that covered approximately 140 pages, and the administration of the questionnaire required on average 40 minutes. The questions were broken down into two sections. The first section related to individual behaviors and attitudes, and was divided into four areas: managing money, planning ahead, choosing products and staying informed. A factorial analysis allowed the FSA to estimate the incidence of every behavior on virtuous money management. Consistently, a score was assigned to each answer based on a scale ranging from 0 to 100: 0 pointed to the lack of any concept or idea correlated to the financial world, while 100 pointed to a full compliance with precepts of good management. The reported scores highlighted two critical areas in planning ahead and in comparing products. With reference to both areas, over $50 \%$ of the respondents failed to exceed 50 points (FSA, 2006). The second section of the questionnaire provided for 7 multiple-choice questions that aimed at measuring the respondents' basic financial capability. In this case, the results were more encouraging: $21 \%$ of the respondents answered all the questions correctly, while $66 \%$ were assigned a score in excess of 75.

Since 2002, ANZ - an Australian banking group - has organized a triennial survey to establish the community's financial literacy. The last report dates back to 2008 and is based on the telephone interview of 2,248 persons over 18 years of age spread throughout the national territory. The survey had recourse to a questionnaire comprising 145 open and multiple-choice questions that covered 56 pages. On average, each interview took little less than 30 minutes. A score ranging from +2 and -2 was assigned to each answer, depending on its compliance with the principles of good money management. The report specified that the maximum score was 131 and that, on average, the respondents scored 83.1 (63\% of the best possible result). The largest gaps were found in the area of the rights and responsibilities applicable to users of financial services.

The surveys that have been conducted are united by a few common findings. Youths in the 18-24 age group, the unemployed, singles, the less well-to-do, individuals over 70 and the ethnic minorities usually feature considerable gaps. Men often show a greater capability than women. Quite often, those who state that their financial education comes from everyday practice feature greater knowledge and capability than those who were school educated. Furthermore, there is a positive correlation between the level of individual education and the use of financial products.

Various scholars uphold that the poor performance results that have been ascertained are not representative of the actual dissemination of financial education among the populations and, in fact, they believe that the financial literacy level is higher. Scholars point to the limits of the survey techniques (Lusardi, 2008), as the latter investigate for the most part basic education, while neglecting capability and personality that, according to researchers, succeed in exalting or repressing individual expertise. A few techniques try to obviate this limitation by concentrating on financial practices and the use of products. Unfortunately, quite often there are no suitable tools to evaluate the opportunity of specific behaviors. Hence, judgments decline to the level of estimates of the consistency between ascertained practices and behaviors that, no matter what, are considered virtuous: high saving rates, lower indebtedness, punctuality in payments.

A further explanation relates to the difficulties in building data sets that represent individual choices with a wealth of information that allows ascertaining the determinants of financial decisions (Martin, 2007). Unlike corporate-related data, such information is not directly available and needs to be surveyed. The collection is unquestionably costly and may only be occasional, to the detriment of the data surveying experiences. Furthermore, the data collection is hindered by the consumers' reluctance to provide personal information.

The second field of the financial education research relates to the applications designed to evaluate the effectiveness of the educational initiatives. Their number is limited and the analyses involve for the most part younger population groups. The following paragraph shall refer in chronological order to the most representative studies, providing 
details on the relative survey methods. Such information proves expedient to interpret the solutions adopted in the empirical analysis of section 4 .

Chen and Volpe are among the first few scholars who dealt with the effectiveness of educational programs. In 1998, the two authors investigated the determinants of the financial literacy of a few groups of college students, hoping to ascertain a considerable impact of the financial education initiatives. Chen and Volpe administered by mail 924 questionnaires, including 36 multiple-choices questions on personal finance topics. The survey involved 13 campuses, located for the most part in the eastern part of the United States. A score equal to the percentage of correct responses was assigned to each questionnaire and the collected data were processed by means of a logistic regression model. The dependent variable is dichotomous and relates to scores higher than or below the median score. The explanatory variables that were adopted were the academic discipline (business or non-business majors) and class rank. Chen and Volpe introduced a few socio-demographic control variables, including gender, age, race, nationality, work experience, and income. Curriculum, class rank, age and work experience prove statistically significant. Unfortunately, the signs of the variables show clear contradictions that do not allow advocating the contribution of education to personal growth.

In 2004, Worthington investigated the determinants of financial knowledge. He used the data collected in 2002 by ANZ, an Australian banking group, which he analyzed through an ordered logistic regression model. The author adopted the score assigned to each questionnaire as the dependent variable. Worthington identified four groups of explanatory variables. The first group comprised a few proxies for characteristics exposing respondents to financial literacy, including in particular such variables as gender, age, household structure, area of residence, ethnic background, language skills, and access to labor. The second group related to school education, while the third reflected the experience resulting from the active participation in the capital market through the use of specific products such as mortgage loans. The fourth group of variables related to income, consumption and household investments; the underlying assumption was that a greater availability promotes literacy in view of the higher costs of poor management. The statistical evidence suggests a higher financial literacy in the 50-60 age group, as well as among professionals or managers, and those who have a university degree and a higher level of income and savings. On the other hand, the financial literacy is lower among women, the unemployed and individual looking for the first time for a job.

In 2007, Elliehausen, Lundquist and Staten examined the impact of credit counseling sessions on borrowing. The sessions (face-to-face or by telephone, lasting nearly 60 minutes) were organized in 1997 by five member agencies of the National Foundation for Credit Counseling and involved the metropolitan areas of Atlanta, Detroit, San Francisco, Phoenix and Dallas. The collected data related to the credit profile of 73,880 consumers, of which 7,979 participated in the counseling sessions. The profiles were provided by the Trans Union credit bureau and were kept under observation from June 1997 to June 2000. Data were evaluated having recourse to a logistic regression model. Several dependent variables were adopted, treating them separately, including the total number of accounts with positive balances, as this variable is better suited to the statistical model. Improvements in the credit profiles were associated with the participation in the counseling sessions, even though most of the improvement was due to the consumers' specific characteristics.

The surveys that have been conducted are united by a few common findings. As for the methods of analysis, most surveys have recourse to regression equations that have to interpret the financial literacy determinants. As for the results, no study succeeds in substantiating the contribution of conventional education to personal growth: while education often proves significant, it is just as significant as other components, first of all experience. The latter appears in the form of various explanatory variables: sometimes as the use of financial products, other times as presence in the labor market. A plausible justification is that there are different channels through which experience is gained. At any rate, what seem to have a special effect are the lessons and the rules of the household, which filters and promotes experience. 
As for the limits shown by the surveys, the studies feature the same weaknesses as the first research field, and they are compounded by the numerousness and geographic distribution of the samples being examined, not infrequently more circumscribed, with a regression equation capacity to explain on average no more than $20-22 \%$ of the phenomenon being studied. At times, the formulations involve judgments on the initiative expressed by the participants. These judgments can be affected by the wish to justify one's involvement in useful initiatives and to refrain from questioning programs promoted by the government or by one's company. This may cause the findings to be distorted. Quite commendable is the effort made within the context of a few analyses to evaluate after a number of years the repercussions of the participation in educational sessions, since this allows keeping into account the long time required by the precepts to be metabolized. Regrettably, as the period of observation is extended, it proves harder to isolate the involvement of specific factors. This is documented by the limited statistical significance of the models.

No study tested the contribution to financial decisions of the access to information. The reasons for this should be looked for in the want of tools suitable for evaluating the opportunity of specific behaviors. Quite recently, a few steps forward have been made in the selection of amortization schedules. Kamleitner and Kirchler (2007) suggested that the choice of a consumer loan represent the final act of a more comprehensive process that usually comprises five phases. The first phase corresponds to the perception of the need to borrow. The second phase focuses on the search of information about loan alternatives, singling out lenders and amortization schedules and collecting data on characteristics and prices. The decision to underwrite a loan is made after having examined, in the third phase, the collected information, and having rated, in the fourth phase, the available alternatives. Bettman, Luce, and Payne (1998) reported that consumers use (more or less consciously) a repertoire of decision-making rules to assess and compare the available options. Quite a number of applications that followed the contribution of these three authors examined the comparison among lenders and presented significant substantiations. Unfortunately, the lenders' choice often depends on subjective opinions with respect to which it is hard to determine the opportunity of the decision. Differently, the selection criteria applied to amortization schedules feature a higher level of objectivity, even though they represent an area that has been just recently explored. Economic conditions are the characteristic more frequently reported as the determinant of one's choice. In particular, the annual percentage rate (APR) is the most frequently mentioned term (FSA, 2001).

The use of a questionnaire is a common factor shared by surveys dealing with a comparison among amortization schedules. The questionnaire is usually filled in during faceto-face interviews as this ensures the quality of data. The questions relate to the recollection of past events, behaviors that consumers are likely to adopt and information deemed expedient for a comparison. Exercises (included among the questions) often provide a sound support to the surveys (Ranyard et al., 2006), as they allow a direct substantiation of choices and detect the capability of consumers to apply their knowledge. Unfortunately, most surveys are brought together by the lack of an explicit link between the selected option and its worth. Lacking this link, the decision-making performance may be measured at the most in terms of stability of the choices varying the available information.

The NPV allows to estimate the worth of financing choices. Moreover, its calculation enables discrimination between credit alternatives, giving preference to those that present greater NPV.

$$
\begin{aligned}
& \text { Amount borrowed }=\sum_{k=1}^{n} \text { Monthly_installment } \times(1+A P R)^{-k} \\
& \text { NPV = Amount borrowed }-\sum_{k=1}^{n} \text { Monthly_installment } \times(1+\text { opportunity_cos } t)^{-k}
\end{aligned}
$$

The limit of NPV resides primarily in the discretionary selection of the return on capital that determines its value. The solution adopted in the present work is equating the discount rate with the average annual percentage charges calculated by authorities to identify the usury threshold rates. Bank of Italy calculates these average rates, which calls 'TEGM' 
(Tasso Medio Effettivo Globale). These measures correspond to weighted means of all market charges. Each charge weighs upon on the basis of the number of transactions carried out by informer lenders. Consequently, is the most probably rate charged to an applicant. For greater details, refer to Caratelli (2010).

\section{Data and methodology}

The empirical research designed to single out the major determinants of borrowing choices has been conducted with a consolidated methodology, commonly used in preceding studies: the administration of a questionnaire and the subsequent statistical analysis of the resulting answers through a more or less complex regression model.

\section{The administration of the questionnaire}

The process of selecting from among a variety of loan alternatives has been investigated having recourse to a questionnaire administered during 2009 to 299 individuals. During the initial phase of the study, this set of respondents did not represent an actual sample constructed according to the statistical random selection logics, nor did it represent the entire Italian population. Indeed, it was the outcome of information passed along by word of mouth that ended up involving 148 students of the Faculty of Economics of Roma Tre University in addition to 151 persons with a variety of profiles, including workers in dependent employment, self-employed workers, unemployed persons and pensioners. The main descriptive statistics are shown in Tables 1 and 2.

With a view to carefully monitoring the information collection process, the questionnaire has always been administered to limited groups of individuals. Moreover, the questions have been asked directly by the researchers who have conducted the study, personally taking down the answers in order to reduce any inconsistency problem and error.

The respondents were given a questionnaire comprising 5 questions, each one proposing a choice from among a number of loan proposals. Following the scheme proposed by Ranyard et al. (2006), the alternatives to be compared made up the lines of a matrix and were described through combinations of data (the columns of the matrix) relative to the amount of the loan, the duration and several cost indicators. Additional information that was likely to affect the choice, such as the reputation of the intermediary and its location, was intentionally omitted in order to restrict the field of the survey to the respondents' capability to select the best proposal from the point of view of the pure economic expedience. For each series of alternatives, the respondents were requested to express a preference; however, they were also entitled to refuse all the proposals or to notify their indifference with respect to the choice. On the other hand, the respondents did not have the option of not answering at all, to avoid that they might refrain from the taking a position whatsoever.

In order to evaluate the effect of the amount and quality of available information on the actual choice, the questionnaires were constructed with various sets of data relative to the loan alternatives and, consistently, the respondents were classified in three different groups. Group A was only provided with basic information and, in addition to the loan amount and duration, knew the amount of the monthly installment required to repay the loan. Group B also knew the annual nominal rate (ANR) under the contract and the annual percentage rate (APR). Finally, Group $\mathrm{C}$ was also informed about the average overall effective rate charged by lenders, identified by the Bank of Italy in order to determine the usury limit (TEGM), and the total loan cost, that is to say, the overall amount to be paid in order to reimburse the loan.

In addition to the choice from among the different sets of loan alternatives, the questionnaire verified a few fundamental data relative to the respondents' socio-demographic characteristics that had proved decisive in the main surveys on financial literacy (Chen and Volpe, 1998): age, gender, region of residence, marital status, and position within the household, as well as educational qualifications and occupational status. Since the effectiveness of the choice could also depend on the experience gained in financial matters through the use of a few products and services (Elliehausen et al., 2007), even this aspect has been investigated. In particular, the questionnaire aimed at ascertaining whether the respondents owned a bank current account, a bank deposit or postal savings passbook and 
whether they had ever used one or more of eight different financial products/services, the list of which had been defined based on the Bank of Italy survey of household wealth (salary crediting arrangement, payment of utilities, stock custody and management, stock dealing, mortgages, personal loans, assets management and insurance contracts). As observed by Devlin (2002), a simple count of the number of services being used can be an indicator of the experience gained in financial matters. Finally, information about the ownership of debit and credit cards and the frequency of their use was also collected.

Table 1. Composition of the sample

\begin{tabular}{|lcccc|}
\hline & Quest_A & Quest_B & Quest_C & Total \\
\hline Students & 47 & 52 & 49 & 148 \\
Non-students & 50 & 50 & 51 & 151 \\
Total & 97 & 102 & 100 & $\mathbf{2 9 9}$ \\
\hline
\end{tabular}

Quest_A: loan amount, duration, amount of the monthly installment; Quest_B: loan amount, duration, amount of the monthly installment, ANR, APR: Quest_C: loan amount, duration, amount of the monthly installment, ANR, $A P R, T E G M$, total loan cost

Table 2. Profile of respondents: socio-demographic features and financial experience

\begin{tabular}{|c|c|c|c|c|}
\hline \multirow{3}{*}{$\begin{array}{l}\text { Characteristic } \\
\text { Age }\end{array}$} & \multicolumn{4}{|c|}{ Prevalent mode $(\%)$} \\
\hline & \multicolumn{2}{|c|}{ Students (148 respondents) } & \multicolumn{2}{|c|}{ Non-students (151 respondents) } \\
\hline & Less than 25 & $87.16 \%$ & Between 25 and 30 & $39.74 \%$ \\
\hline Gender & Male & $56.08 \%$ & Male & $52.98 \%$ \\
\hline Region & Central Italy & $91.22 \%$ & Central Italy & $74.17 \%$ \\
\hline Marital status & Single & $99.32 \%$ & Single & $60.93 \%$ \\
\hline Position in the household* & Son/Daughter & $97.30 \%$ & Son/Daughter & $48.34 \%$ \\
\hline Educational level & Average & $55.41 \%$ & High & $69.54 \%$ \\
\hline Occupation & Unemployed & $100 \%$ & Clerk/Teacher & $42.38 \%$ \\
\hline Current account & Available & $60.81 \%$ & Available & $95.36 \%$ \\
\hline Bank deposit/Postal savings & Not available & $66.22 \%$ & Not available & $87.42 \%$ \\
\hline Financial experience & $2-5$ years & $37.16 \%$ & More than 10 years & $52.32 \%$ \\
\hline Number of financial services & 0 & $45.95 \%$ & 2 & 25.17 \\
\hline Debt card & Available & $67.57 \%$ & Available & $96.69 \%$ \\
\hline N. of ATM/POS operations ${ }^{* *}$ & Less than 3 in a month & $47.30 \%$ & More than 10 in a month & $50.33 \%$ \\
\hline Credit card & Not available & $75.00 \%$ & Available & $68.87 \%$ \\
\hline N. of credit card payments ${ }^{* * *}$ & Less than 3 in a month & $85.81 \%$ & Less than 3 in a month & $62.25 \%$ \\
\hline
\end{tabular}

* With respect to the head of the family. ** Respondents were classified into three categories on the basis of the number of payments made in a month: less than 3, between 3 and 10, more than 10. *** Respondents were classified into four categories on the basis of the number of payments made in a month: less than 3, between 3 and 6, between 7 and 10, more than 10.

The questions asked to the respondents are outlined below, with the level of detail contained in questionnaire $\mathrm{C}$ and, therefore, with the largest possible amount of information that includes also the TEGM used as the capital opportunity cost for calculating the NPV (during the survey period, the latter amounted to $10.20 \%$ for loans exceeding 6,000 euro and $14 \%$ for loans involving lower amounts). With a view to highlighting the best choice from the point of view of pure economic expedience, the paper shows the NPV corresponding to each alternative; it should be borne in mind that, quite clearly, this information was not provided to the respondents. For those who chose the answer "all the loans are equally expedient", the NPV was calculated as the mean NPV of all the alternative proposals. For those who chose the answer "none of the loans are expedient", the NPV was set at zero (being quite likely that the individual would refrain from underwriting the loan).

Question 1

\begin{tabular}{|ccccccc|c|}
\hline $\begin{array}{c}\text { Non-bank } \\
\text { intermediary }\end{array}$ & $\begin{array}{c}\text { Amount } \\
\text { borrowed }\end{array}$ & Term & $\begin{array}{c}\text { Monthly } \\
\text { installment }\end{array}$ & Total cost & ANR & APR & NPV \\
\hline A & 10,000 & 12 & 901.4 & $10,816.85$ & 14.75 & 15.79 & -264.34 \\
\hline B & 10,000 & 12 & 888.61 & $10,663.30$ & 12.03 & 12.71 & -119.78 \\
\hdashline All alternatives are equivalent & & & & & & & -192.06 \\
\hline All alternatives are not expedient & & & & & 0 \\
\hline
\end{tabular}


The first question had a simple structure: two loan alternatives involved the same amount and the same duration. Consequently, a mere comparison of the monthly installment or the APR amount should have easily allowed selecting the offer of the second financial intermediary, with no significant difference between Group A or B. The TEGM information, only available to Group C, should have instead led to the conclusion that neither loan was expedient, since both intermediaries charged rates that were higher than the mean market rate.

Question 2

\begin{tabular}{|c|c|c|c|c|c|c|c|}
\hline $\begin{array}{l}\text { Non-bank } \\
\text { intermediary }\end{array}$ & $\begin{array}{c}\text { Amount } \\
\text { borrowed }\end{array}$ & Term & $\begin{array}{c}\text { Monthly } \\
\text { installment }\end{array}$ & Total cost & ANR & APR & NPV \\
\hline $\mathrm{A}$ & 5,000 & 12 & 445.95 & $5,351.45$ & 12.73 & 13.50 & 11.53 \\
\hline A & 5,000 & 36 & 167.82 & $6,041.56$ & 12.73 & 13.50 & 17.87 \\
\hline A & 5,000 & 60 & 113.08 & $6,784.58$ & 12.73 & 13.50 & 19.12 \\
\hline B & 5,000 & 12 & 444.30 & $5,331.62$ & 12.02 & 12.71 & 29.81 \\
\hline B & 5,000 & 36 & 166.32 & $5,987.63$ & 12.11 & 12.80 & 42.95 \\
\hline B & 5,000 & 60 & 112.62 & $6,757.33$ & 12.55 & 13.30 & 26.77 \\
\hline $\mathrm{C}$ & 5,000 & 12 & 450.70 & $5,408.44$ & 14.75 & 15.79 & -41.02 \\
\hline $\mathrm{C}$ & 5,000 & 36 & 172.12 & $6,217.81$ & 14.75 & 15.79 & -63.62 \\
\hline $\mathrm{C}$ & 5,000 & 60 & 118.30 & $7,097.79$ & 14.75 & 15.79 & -68.04 \\
\hline \multicolumn{7}{|c|}{ All alternatives are equivalent } & -2.74 \\
\hline \multicolumn{7}{|c|}{ All alternatives are not expedient } & 0 \\
\hline
\end{tabular}

The second question was characterized by a more complex structure, proposing a choice of nine loans offered by three different lenders. First of all, the comparison of the conditions applied to the same expiry dates, in terms of rate or installment amount, should have allowed the respondents to single out the finance company B as the one offering the best conditions, being the amount and duration of the loan equal. Later on, based on what was defined as the second precept, the 36-month loan should have been chosen since, although having a slightly higher APR than the alternative 12 month-loan, its rate was below the mean market rate and it had a longer-dated maturity and, therefore, it had a higher NPV.

\begin{tabular}{|c|c|c|c|c|c|c|c|}
\hline \multicolumn{8}{|c|}{ Question 3} \\
\hline $\begin{array}{c}\text { Non-bank } \\
\text { intermediary }\end{array}$ & $\begin{array}{l}\text { Amount } \\
\text { borrowed }\end{array}$ & Term & $\begin{array}{l}\text { Monthly } \\
\text { installment }\end{array}$ & Total cost & ANR & APR & NPV \\
\hline $\mathrm{D}$ & 3,500 & 6 & 600.82 & $3,604.95$ & 10.21 & 10.70 & 29.30 \\
\hline D & 3,500 & 18 & 210.54 & $3,788.65$ & 10.21 & 10.70 & 43.05 \\
\hline $\mathrm{D}$ & 3,500 & 42 & 99.46 & $4,177.14$ & 10.21 & 10.70 & 46.97 \\
\hline \multicolumn{7}{|c|}{ All alternatives are equivalent } & 39.77 \\
\hline \multicolumn{7}{|c|}{ All alternatives are not expedient } & 0 \\
\hline
\end{tabular}

In this case, the choice was from among three loan alternatives proposed by the same finance company with the same APR below the mean market rate. Therefore, the choice should have fallen on the loan having the longest term of maturity. In any event, one needs to consider that Group A only knew the amount of the installment: therefore, they could not be aware of the fact that the APR was the same regardless of the expiry. Furthermore, only Group $\mathrm{C}$ had access to the information that was to allow them to recognize the expedience of the conditions and, therefore, to appreciate the lengthening of the expiry.

Question 4

\begin{tabular}{|c|c|c|c|c|c|c|c|}
\hline $\begin{array}{l}\text { Non-bank } \\
\text { intermediary }\end{array}$ & $\begin{array}{c}\text { Amount } \\
\text { borrowed }\end{array}$ & Term & $\begin{array}{l}\text { Monthly } \\
\text { installment }\end{array}$ & Total cost & ANR & APR & NPV \\
\hline$E$ & 3,500 & 6 & 603.33 & $3,619.95$ & 11.66 & 12.30 & 15.01 \\
\hline $\mathrm{E}$ & 3,500 & 18 & 213.32 & $3,839.70$ & 11.93 & 12.60 & 18.15 \\
\hline E & 3,500 & 42 & 103.71 & $4,355.67$ & 12.73 & 13.50 & 7.05 \\
\hline \multicolumn{7}{|c|}{ All alternatives are equivalent } & 13.40 \\
\hline \multicolumn{7}{|c|}{ All alternatives are not expedient } & 0 \\
\hline
\end{tabular}


The fourth question proposed three loans with a growing rate and duration. The first two alternatives had nearly the same APR and, in both cases, it was below the market average. Instead, the third alternative had a considerably higher rate and longer duration. The best answer was the 18-month loan that, although characterized by a slightly higher APR with respect to the short-term alternative, was in any event characterized by a rate that was lower than the market average and, therefore, benefited from the longer expiry. It should be noted that there was quite a resemblance with the second step of the choice proposed in question 2.

\begin{tabular}{l} 
Question 5 \\
\begin{tabular}{|ccccccc|r|r|}
\hline $\begin{array}{c}\text { Non-bank } \\
\text { intermediary }\end{array}$ & $\begin{array}{c}\text { Amount } \\
\text { borrowed }\end{array}$ & Term & $\begin{array}{c}\text { Monthly } \\
\text { installment }\end{array}$ & Total cost & ANR & APR & NPV \\
\hline F & 3,500 & 12 & 309.21 & $3,710.58$ & 10.93 & 11.49 & 40.74 \\
\hline F & 3,500 & 36 & 109.39 & $3,938.12$ & 7.82 & 8.11 & 149.25 \\
\hline All alternatives are equivalent & & & & & & 95.00 \\
\hline All alternatives are not expedient
\end{tabular} \\
\hline
\end{tabular}

The fifth question had a simple structure and presented a comparison between two loan alternatives where the second one was characterized by a considerably lower APR and a much longer expiry. Hence, in the light of both the first and the second selection criterion, the second proposal should have been chosen. Furthermore, since the proposed rates were below the mean market value, the knowledge of the TEGM should not have played a decisive role.

As anticipated in the preceding sections, the NPV criterion had been adopted in order to evaluate the effectiveness of the respondents' choices. However, the latter depended on the characteristics of the proposed loans, in terms of loan amount, contractual duration and applicable rate. It ensues that the NPV obtained in a certain question, as well as the NPV "lost" with respect to the optimum choice, could have been values that were not comparable to those relative to another set of choices. Then, what was needed was a measure allowing a comparison of the score obtained in each question, a sort of an index number independent of the characteristics of the individual loans, obtained according to the following formula:

$$
\text { score }=\frac{N P V_{\max }-N P V_{\text {real }}}{N P V_{\text {max }}-N P V_{\text {min }}}
$$

where $\mathrm{NPV}_{\max }$ is the value relative to the optimum choice, $\mathrm{NPV}_{\text {real }}$ is the value relative to the answer given by the respondent, and $\mathrm{NPV}_{\text {min }}$ the value relative to the worst alternative. It is easy to observe that the numerator represents the NPV lost due to the likely ineffectiveness of one's choice and the denominator is the range of variation between the best and the worst alternative. Therefore, the score value is 0 in case of an excellent choice and 1 in case the worst alternative is selected. Since quite a number of surveys investigating the level of financial education tend to stress the gaps in the individuals' financial literacy, as well as the consequences of decisions taken without having full awareness, we have decided to define a measure that was to provide immediate evidence of the NPV lost with respect to the best choice. The construction of this index has also allowed adding together the scores obtained from the various answers and, therefore, calculating an overall performance measure.

Table 3. Scores of respondents by type of questionnaire

\begin{tabular}{|c|c|c|c|c|c|c|c|c|}
\hline & \multicolumn{2}{|c|}{ Total } & \multicolumn{2}{|c|}{ Quest_A } & \multicolumn{2}{|c|}{ Quest_B } & \multicolumn{2}{|c|}{ Quest_C } \\
\hline & Mean & Std Dev & Mean & Std Dev & Mean & Std Dev & Mean & Std Dev \\
\hline Score_1 & 0.3717 & 0.2010 & 0.3990 & 0.1779 & 0.3750 & 0.1973 & 0.3417 & 0.2225 \\
\hline Score_2 & 0.1530 & 0.1448 & 0.1426 & 0.1529 & 0.1534 & 0.1263 & 0.1625 & 0.1550 \\
\hline Score_3 & 0.2569 & 0.2660 & 0.3018 & 0.2903 & 0.2101 & 0.2406 & 0.2615 & 0.2610 \\
\hline Score_4 & 0.2588 & 0.3148 & 0.2817 & 0.3429 & 0.2672 & 0.3129 & 0.2285 & 0.2881 \\
\hline Score_5 & 0.3172 & 0.3778 & 0.4885 & 0.3756 & 0.2237 & 0.3571 & 0.2481 & 0.3468 \\
\hline Score_tot & 1.3580 & 0.7714 & 1.6131 & 0.8187 & 1.2290 & 0.7513 & 1.2423 & 0.6871 \\
\hline
\end{tabular}

In each question, the respondents lose a rather sizable share of the attainable NPV, with a mean score that ranges between 0.1530 of question 2 and 0.3717 of question 1 . Furthermore, it may be noted that the type of questionnaire affects to a considerable extent the 
end results, given that the scores obtained by Groups A, B, and C are quite different. With a view to ascertaining that such gaps were not fortuitous and determining their statistical significance, we have proceeded with a difference of means test (t-test) with respect to the total score. The test results have highlighted a significant gap between the score obtained on average by the Groups A and B (p-value $=0.001)$ and the Groups A and C (p-value $=0.002)$, while no significant differences could be noted between Groups B and C. This is a rather significant indication of the relevance of the quality and quantity of the information provided. Since the score obtained in the questionnaire could also be affected by the socio-demographic profile of the respondents and their financial experience, one has to analyze the answers through a model that takes all these aspects simultaneously into consideration.

The methodology of analysis of the answers

Starting from the consideration that the knowledge and tools available to respondents represent the "initial store" with which each individual confronts the entire questionnaire, we have decided to develop a system of five simultaneous equations where the endogenous variables are represented by the scores obtained in the various questions. In different words, since the score obtained in each question depends on the peculiarities of the question rather than on a different way in which the problem is approached, the variability of each score must be evaluated within a system of answers that also involves all the other questions.

The System of Simultaneous Equations (SEM) comprises five equations where, in each one of them, the purely endogenous variable is the score obtained in the question, while the purely exogenous variables are those drawn from the questionnaire being administered or inferred from official sources. The following variables were included in order to consider the socio-demographic profile of the respondents:

- Age bracket; Gender; Residence; Marital status; Position in the household; Educational level; Occupation.

These are followed by the variables that identify the experience of the individuals with respect to the ownership and the use of a few financial tools:

- Ownership of a current account; Ownership of a deposit passbook; Financial experience (since how many years has the respondent had recourse to a bank or a post office); Number of financial services; Use of a debt card and monthly number of ATM/POS operations; Use of the credit card and monthly number of operations.

The questionnaire did not include questions concerning the wealth and the financial position of either the respondents or their households, given their natural reticence to disseminating this type of information. Besides, it should be borne in mind that nearly half of the respondents were students and, therefore, they might not be fully aware of the economicfinancial situation of their households. In any event, these are factors that are likely to have a significant effect on the individual's behavior, as reported in previous studies (Worthington, 2004). Data resulting from the 2008 Bank of Italy survey of the wealth of the Italian households have been used with a view to overcoming these limitations and testing the influence, if any, of income or property. As for the variables under consideration, each respondent was assigned a value equal to the mean resulting from the said survey for individuals having the same profile based on age, gender, region of residence and occupation. This allowed the entry of additional regressors such as:

- Income. The variables that have been constructed relate to the yearly income available at the level of both the individual and the household. With reference to the former, the study succeeded in tracing details of the income from capital while, with reference to the latter, due consideration was given to the breakdown between consumption and saving;

- Household wealth. In addition to the total value of the household property, the study succeeded in breaking it down into real assets, financial assets and financial liabilities.

The set of purely exogenous variables is combined with a group of dichotomous variables obtained from the survey which have a definite significance for our study, namely:

- the dichotomous variable Stud, the value of which is 1 for students and, otherwise, 0;

- the Quest_A, Quest_B and Quest_C variables, which identify the 3 types of questionnaire. The dummy omitted to avoid multicollinearity problems is Quest_A, so 
that the coefficients assumed by the other two must be interpreted with respect to the questionnaire with the least quantity of information (A).

Besides, the exogenous variables that were entered in each one of the system equations were the scores obtained for all the questions, other than the one taken as the endogenous variable, in order to get - as previously pointed out - to the simultaneous effect of the phenomenon, that is to say, the fact that having answered one of the questions in a certain way certainly depends on the way the other four questions were answered.

The unknown SEM parameters were estimated through the recourse to the Three Stage Least Squares method (3SLS).

\section{Results}

In terms of goodness of fit of the model, the results that have been obtained do not point to very high R-Squared index values. However, they are perfectly in line with the findings of preceding studies, although the latter were based on larger samples. The regressors included in each equation were selected on the strength of a stepwise procedure, with a view to improving the fit of the model and, at the same time, cause the latter to make sparing use of variables and, therefore, cause it to be more easily interpreted.

With reference to all the five equations - except for question 2 - the dichotomous variables regarding the type of questionnaires (Quest_B and Quest_C) proved significant, and this confirms that the amount of information provided to the user of financial services affects in a significant manner the total score. With a view to gaining an improved understanding of the role of information, it may prove expedient to refer however briefly to the structure of the question and consider how the answers in Groups A, B, and C are distributed.

Table 4. Results from the Simultaneous Equation Model with Three Stage Least Squares (3SLS) estimation

\begin{tabular}{|c|c|c|c|c|c|c|c|}
\hline Score_1 & Coeff & p-value & \multicolumn{2}{|l|}{ Score 2} & \multicolumn{2}{|r|}{ Coeff } & p-value \\
\hline Quest_C & -0.059 & 0.012 & \multicolumn{2}{|l|}{ Score_3 } & \multicolumn{2}{|r|}{0.154} & 0.147 \\
\hline Age $25-30$ & 0.039 & 0.091 & \multicolumn{2}{|l|}{ Score 4} & & 0.201 & 0.010 \\
\hline Spouse & 0.092 & 0.026 & \multicolumn{2}{|c|}{ Household Consumption } & & -0.000002 & 0.035 \\
\hline Other_household_component & 0.132 & 0.037 & \multicolumn{2}{|l|}{ _cons } & & 0.139 & 0.008 \\
\hline Unemployed & 0.101 & 0.000 & & & & & \\
\hline Debt card & 0.065 & 0.028 & & & & & \\
\hline Atm Pos & -0.003 & 0.017 & & & & & \\
\hline Score_4 4 & -0.294 & 0.014 & & & & & \\
\hline Score_5 & 0.077 & 0.221 & & & & & \\
\hline cons & 0.342 & 0.000 & & & & & \\
\hline Score 3 & Coeff & p-value & \multicolumn{2}{|l|}{ Score 4} & & Coeff & p-value \\
\hline Stud & -0.053 & 0.076 & \multicolumn{2}{|l|}{ Quest_C } & & -0.069 & 0.025 \\
\hline Quest_B & -0.043 & 0.111 & \multicolumn{2}{|c|}{ Self_employed } & & 0.232 & 0.016 \\
\hline Divorced_Widow & 0.124 & 0.100 & \multicolumn{2}{|c|}{ Pensioner } & & 0.307 & 0.021 \\
\hline Self_employed & -0.134 & 0.139 & \multicolumn{2}{|l|}{ Unemployed } & & 0.102 & 0.015 \\
\hline N_financial_services & -0.013 & 0.193 & \multicolumn{2}{|c|}{$\mathrm{N}$ financial services } & & 0.017 & 0.111 \\
\hline Score_2 & 0.694 & 0.081 & \multicolumn{2}{|c|}{ Credit card } & & 0.078 & 0.019 \\
\hline Score_1 & -0.227 & 0.263 & \multicolumn{2}{|l|}{ Score_2 } & & 0.684 & 0.125 \\
\hline Score_4 & 0.102 & 0.581 & \multicolumn{2}{|l|}{ Score_3 } & & 0.256 & 0.354 \\
\hline Score_5 & 0.167 & 0.042 & \multicolumn{2}{|l|}{ Score 1} & & -0.397 & 0.120 \\
\hline cons & 0.218 & 0.056 & \multicolumn{2}{|l|}{ Score_5 } & & 0.034 & 0.760 \\
\hline & & & \multicolumn{2}{|l|}{ _cons } & & 0.120 & 0.384 \\
\hline Score 5 & Coeff & p-value & Equation & R-sq & chi2 & \multicolumn{2}{|c|}{ p-value } \\
\hline Quest B & -0.141 & 0.022 & \multirow{6}{*}{$\begin{array}{l}\text { Score_1 } \\
\text { Score_2 } \\
\text { Score_3 } \\
\text { Score_4 } \\
\text { Score_5 }\end{array}$} & 0.2481 & 65.46 & \multicolumn{2}{|c|}{0.000} \\
\hline Quest_C & -0.153 & 0.009 & & 0.1628 & 24.27 & \multicolumn{2}{|c|}{0.000} \\
\hline Male & -0.116 & 0.002 & & 0.3033 & 38.26 & \multicolumn{2}{|c|}{0.000} \\
\hline Divorced_Widow & -0.329 & 0.014 & & 0.4099 & 56.69 & & 000 \\
\hline Fin_exp $>-10$ years & -0.134 & 0.003 & & 0.2422 & 94.64 & & 000 \\
\hline Credit_card & -0.068 & 0.137 & & & & & \\
\hline $\mathrm{N}$ paym ccard & -0.009 & 0.150 & & & & & \\
\hline Score_3- & 0.940 & 0.023 & & & & & \\
\hline Score 4 & -0.004 & 0.990 & & & & & \\
\hline Score_1 & 0.643 & 0.108 & & & & & \\
\hline Individual_income & 0.00001 & 0.007 & & & & & \\
\hline Unearned income & -0.0001 & 0.023 & & & & & \\
\hline Household consumption & 0.00001 & 0.070 & & & & & \\
\hline cons & -0.141 & 0.670 & & & & & \\
\hline
\end{tabular}

A coefficient $>0$ shows a direct relationship with our score and so a negative relationship with the performance.

With reference to question 1 , the frequencies appear to be rather polarized, concentrating on the "seemingly" more correct answer, that is the loan proposed by the 
finance company B (12 months, APR 12.71\%), which has a rate and an installment amount that are lower than those of alternative A (12 months, APR 15.79\%). Although Group C, having access to the TEGM information, registered an advantage with respect to Groups A and $\mathrm{B}$, a rather limited share (about 27\%) of them reached the conclusion that neither proposal was expedient because the relative APR was higher than the TEGM $(10.20 \%$ for amounts higher than 6,000 euro). Therefore, it seems reasonable to state that the respondents succeed in applying the first precept correctly in just a partial manner. In fact, although they succeed in identifying the proposal with the lower APR, they are often unable to use the information coming from the market. The results of the SEM model, which take into account also all the respondent's profile variables and the scores obtained in the other questions, confirm the advantage of those who have access to the TEGM information. As a matter of fact, only the coefficient of the dummy that identifies questionnaire $\mathrm{C}$ proves significant and with a negative sign, while no significant differences are found between Groups A and B. After all, in case of loans with the same amount and duration, it is natural to expect that the knowledge of either the rate or the amount of the installment is completely equivalent.

With reference to question 2, most of the respondents succeeded in properly identifying the lender offering the best conditions, and the three Groups relative to questionnaire A, B and C did it in much the same way $(82.3 \%, 81.4 \%$ and $79 \%$, respectively). Since the NPVs associated to the three loan alternatives proposed by the "best" finance company were not too different, the outcome was a rather homogeneous score for all the respondents. This consideration can lead to an improved understanding of the reason why the second question is the only one in respect of which the SEM fails to highlight a significant role of the dichotomous variables relative to the available information.

With reference to the third question, the individuals in Group A are particularly concentrated on the shorter expiries, and only $8.3 \%$ of them chose the 42-month loan that, having the same rate as the other ones (lower than the TEGM) but a longer duration, is the alternative with highest NPV. It is quite likely that the mere information about the amount of the installment does not allow the Group A to recognize that the rate is the same for all the loans and this causes them to choose the closest expiries, even in view of the limited amount being borrowed and, therefore, the bearable installment even for short durations. The individuals belonging to Group B appear to be considerably affected by the knowledge of the rate, so much so that they are spread almost evenly on the different expiries and a sizable share (about 28.4\%) declares that all the alternatives are equally expedient. The individuals of Group $\mathrm{C}$ appear to be affected by the knowledge of the total cost. In fact, the answers focus once again on the shortest expiry that, although entailing the lowest total cost, does not represent the alternative with the highest NPV. This is an important indication of how the second choice criterion is not adopted with the same automatism and simplicity as the first one. Once again, it would seem that information plays a decisive role, even in view of the socio-demographic profile of the respondents. In fact, the SEM results point to a significant advantage for Group B. In view of the above, a greater amount of information does not always lead to a more effective choice and, indeed, it may engender an overload effect.

With reference to question 4, those who have been administered questionnaire A are quite concentrated on the two first alternatives (chosen by $37.5 \%$ and $33.3 \%$ of respondents, respectively), the second of which represents the optimum choice, being characterized by a longer expiry in the face of a very limited APR increase. Not knowing the rate, it is quite likely that the individuals in Group A make their choice based on their wish to avoid running into debt for an excessively long period of time, also in view of the relatively limited amount being borrowed. On the other hand, Group B appears to be rather affected by the knowledge of the rate, given that $54 \%$ of the respondents chose the first proposal with a lower APR and a shorter expiry. Only $23 \%$ of them chose the alternative with the highest NPV. Group C, probably driven also by the information about the total cost, decisively chose the two first alternatives, with a rather similar NPV, resolutely discarding the loan with the longest expiry (chosen only by $4 \%$ of the individuals with respect to $9.4 \%$ in Group A), with a limited share of undecided respondents for whom no loan is expedient (10\% against nearly $15 \%$ in Group A). The SEM results confirm once again the highly significant role of information, with an 
advantage for those who have answered questionnaire $\mathrm{C}$.

With reference to question 5, those belonging to Group A chose quite frequently (45.8\%) the alternative with a higher rate and a short expiry and, therefore, with a low NPV, probably conditioned by the lack of information about the APR relative to the two proposals. The knowledge of the rate appears determinant: $68.6 \%$ and the $64 \%$, respectively, of Group B or $\mathrm{C}$ ended up selecting the second alternative. The SEM results confirm the decisive role of the information available at the time of the selection. Both variables (Quest_B and Quest_C) that identify the questionnaires providing information about interest rates are significant.

In a word, the information available when making a decision has a decisive role, regardless of the more or less comprehensive structure of the question and the respondent's profile. The choices made by the respondents highlight their ability to select the alternative with the lowest rate, but also show that the information provided by the TEGM is not often used consistency with the second precept. Additional signs of the limited capability of the respondents may also be detected. Quite often, it seems that those who have only access to the installment information are unable to trace back the loan rate and decide based on considerations other than the economic expedience (sustainability of the installment or aversion for long-term debt). On the other hand, those who have access to the total cost figure are often affected by it to a considerable extent, and end up choosing the alternative with the shorter expiry, independently of the more or less competitive rate conditions.

Moving to an analysis of the main findings relative to both the socio-demographic and the financial experience variables, the SEM provides other important indications. An especially interesting and partly unexpected result is the lack of any relevant impact of the variables that are indicative of the level of education and that fail to appear in the five equations with a statistically significant coefficient. This finding is also supported by the result relative to the dummy Stud that identifies university students majoring in economics. This dummy proves significant, pointing to an advantage for that category only in respect of question 3. Therefore, there is no significant evidence of an improved performance of those who should have had a better knowledge of financial matters that the mean value for the respondents. There are also further indications of the poor role played by education in determining the effectiveness of loan choices. In question 1, the individuals in the 25-30 age bracket have scored a poorer performance than the reference category (the dummy omitted to avoid multicollinearity problems), that is to say, the respondents under 25 years of age. Analyzing this share of respondents, it may be noted that it comprises 75 individuals, of which a good 63 have a university degree. Then, if their high educational qualifications do not benefit them, it is but natural to wonder what makes their performance even worse than that of other age brackets. This could be caused by the lower experience gained in the management of their budget and financial needs, due (presumably) to their recent access to the labor world and the beginning of an autonomous life with respect to their family of origin. Such an assumption is backed up by the results relative to other socio-demographic variables concerning one's position inside the household and one's occupational condition. With reference to the first dimension, it is interesting to note how the spouse (Spouse) and other household members (Other_household_component) reported a poorer performance than the head of the household, identified as the person who has the higher income and, quite likely, takes the most important decisions on money management matters. The coefficient for the dummy identifying the unemployed (Unemployed) would seem to lend even greater support to the assumed relevance of experience in managing one's budget, as it shows that those who are outside the labor market obtain a poorer performance of those who are employed (a result confirmed also by the equation concerning the fourth question). In any event, the dummy should be interpreted as an advantage with respect to the omitted category. Dealing with individuals belonging to the working class, which quite probably lack any special knowledge of financial matters, the result is even more interesting. Other studies (Peng et al., 2007) have found sounder financial capabilities among those who had their financial training in everyday practice rather than through school curricula. Furthermore, it should be stressed that the questionnaire does not aim at verifying knowledge, as it was designed to survey the capability of taking responsible decisions in the context of a set of alternatives simulating real choices. 
Other indications worthy of note come from the variables relative to the financial experience. In question 5, it was found that those who have used the bank or the post office for over 10 years (Fin_exp>10years) and those who frequently use a credit card (Credit_card and $N \_$paym_ccard) are advantaged. In any event, the result relative to the credit card seems to be contradicted by the finding relative to question 4. As a matter of fact, those who frequently use a credit card, especially those with revolving arrangement, could have developed a tendency to dilute over the time the repayment of their debts. In question 3, the preference for the longest expiries leads to the optimum choice, while the opposite occurs in question 4 . The response relative to the number of financial services used ( $N \_$fin_serv), the coefficient of which appears only in two cases out of five and with alternate signs, proves quite weak. Finally, with reference to debit cards, the mere ownership (Debt_card) seems to have a negative relation with the respondent's performance, while there is a positive relationship between goodness of the choices and frequency of ATM/POS use (N_Atm_Pos).

The income and assets variables do not appear to have a very significant impact, except for question 5. In this case, it turns out that there is a negative relationship between performance and wealth indicators, such as individual income (Individual_income) and household consumption (Household_consumption). This result could be explained by the fact that the optimum alternative was the one with the longer expiry and the lower installments that, owing to reasons of financial sustainability, could be more frequently chosen by the least well-to-do. On the other hand, the variable relative to household consumption appears with the opposite sign in question 2. Finally, the equation relative to question 5 points to an advantage for those who own a more sizable unearned income (Unearned_income) that may act as proxy for financial experience.

In confirmation of the assumptions made during the model construction stage, the coefficient relative to at least one of the endogenous variables considered in the system proves significant in all the equations; this is tantamount to saying that the score obtained for each question affects the score obtained in the other questions.

The good results attained in this stage of the research with respect to the estimate of the SEM parameters allow us to conclude that the tool being used is well suited for evaluating the phenomenon being studied. This is due to a dual reason. Firstly, it has allowed us to clearly highlight that the different quantity/quality of information provided to the respondent affects to a considerable extent his/her capability of answering correctly and, therefore, of taking rational decisions. Secondly, while estimating the relationships among the variables, the use of a simultaneous equation system allowed us to take into account the aspect - that is not directly measurable - connected with the fact that the respondent answers in a "global" manner to the entire questionnaire, involving in each and every answer all his/her knowledge that does not change from one question to the next other than in consequence of the information that is provided from the outside through the questionnaire.

\section{Conclusions}

This final section summarizes the survey that has been conducted, specifying its implications, limits and likely developments.

The survey has probed into the determinants of borrowing choices with a view to offering policymakers guidance in the adoption of effective tools to protect the users of financial services. The ambit of the study has been confined to consumer credit.

An analysis of the literature on the matter has led to the choice of the determinants that have been taken into account, namely: socio-demographic profile, educational curriculum, work experience and practice in the use of financial services. Notwithstanding the lack of substantiation in the main empirical investigations on financial education, we decided to include the access to information at the time of underwriting a loan among the determinants. Since, by now, there are quite a number of applications that suggest the relevant role played by information, the fact of excluding it could not be justified.

The literature analysis has also provided information on the data collection method. Following the prevailing approach, we have had recourse to a questionnaire distributed in 2009 to 299 consumers. The sizable contributions in the matter of economic expedience of 
loans and those of Bettman et al. (1998) and Ranyard et al. (2006) have allowed the introduction of an innovation in the data survey method. Traditional surveys document capability by having recourse to multiple-choice questions. This paper has documented the capability of taking responsible decisions having recourse to: (i) a set of alternatives that simulates real choices; and (ii) an objective measure of the value of amortization schedules with a view to ordering the economic expedience of each choice in a non-discretionary manner. The fact of having considered the individual capabilities has led to the introduction of a further innovation, this time inherent in the data processing techniques. The settled methodology views the use of a linear regression model as a means to analyze the total score obtained in a questionnaire. This investigation has used a system of simultaneous equations (SEM) comprising as many equations as there are sets of alternatives proposed to the respondents. This system allows investigating each choice in a detailed manner and, at the same time, taking the personality of the respondents into account: consumers react to the different questions by getting involved and by making the most of their knowledge and capability that do not change from one question to the next. This uniqueness would be lost if the answers were treated separately.

As for the implications of the analysis, there are four main indications: the first two are consistent with literature-based findings; the third one apparently contradicts the latter; and the last has, instead, no terms of comparison.

The first indication relates to school and university education, which does not prove determinant. Indeed, one aspect comes as a surprise: the model fails to point to any contribution of education to the respondents' choices. The second indication relates to practice in the use of financial services and working experience. The fact of having had recourse since quite a time to an intermediary promotes individual abilities. On the other hand, the fact of being away from the labor market hinders personal growth. The indication that contradicts previous surveys relates to wealth: when it is significant, it has a negative effect on performance. On the contrary, financial education studies have documented its ability to strengthen expertise: as a matter of fact, a greater availability promotes education in view of the higher costs of poor management. A closer look shows that the negative impact proves reasonable in borrowing choices: wealth may engender disaffection towards credit and, therefore, one has only recourse to it if strictly necessary and cutting to a minimum the loan expiry, to the detriment of the economic expedience. Quite probably, even a shortage of available funds has a negative effect on performance. In this case, a consumer is ready to forgo expedience with a view to fostering the financial sustainability of the loan rather than for disaffection towards credit. Unfortunately, the sample composition does not allow verifying the latter relationship. The final indication relates to the access to information, in respect of which there were no previous suggestions but only conjectures. The information made available upon the subscription of a loan affect choices, and would even seem decisive. What is important is not only the access to data but also information quality and quantity. Therefore, these indications confirm that the impact of conventional education is hard to survey and its effect becomes tangible when the educational programs promote experience and have a practical approach. Furthermore, the findings bear witness to the fact that policymakers should not neglect alternative tools for the protection of consumers. It is advisable to invest on them to ensure an improved effectiveness and to engender shortmedium term effects that are unattainable by financial education.

At any rate, these indications must be considered with all due caution. An improved interpretation of this phenomenon requires an extension of the survey based on a complete and representative sample. This is an exploratory study, as witnessed by the characteristics of the sample and its shortcoming in terms of number of participants. In spite of all this, the significance of the model is in line with (in a few cases, better than) the studies conducted up to now. The respondents were not selected through a probabilistic sampling and their composition is not representative of the Italian population. Besides, the sample is not sufficiently diversified in terms of geographical area and profile of the participants. Quite a few respondents were in the 25 to 30 age bracket. They were singles, unemployed or looking for their first job and, therefore, represented a weak group from the point of view of financial 
education: their capability had had no opportunity to mature, nor had they been able to gain an experience. The moderate disparity of their profiles could explain why their study curricula had no impact on their choices but, at the same time, does not affect the informative value of this study. The latter does not mean to challenge the significance of financial education, but it does recommend a balanced development of tools for the protection of consumers.

\section{References}

ANZ (2008). ANZ Survey of Adult Financial Literacy in Australia. Melbourne, Australia.

Bank of Italy (2010). "Survey on Household Income and Wealth". Issue of the Statistical Bulletin, Febraury, Rome.

Bettman, James R., Mary F. Luce and John W. Payne (1998). "Constructive Consumer Choice Processes." Journal of Consumer Research, Volume 25, Number 3, 187-217.

Caratelli, Massimo (2010). "Transparency in Consumer Credit. The Usage of the APR." Proceedings of the American Society of Business and Behavioral Sciences, Volume 17, Number 1, 35-49.

Chen, Haiyang and Ronald P. Volpe (1998). "An Analysis of Personal Financial Literacy Among College Students." Financial Services Review, Volume 7, Number 2, 107128.

Devlin, James F. (2002). "An Analysis of Choice Criteria in the Home Loans Market." International Journal of Bank Marketing, Volume 20, Number 5, 212-226.

Elliehausen, Gregory, E. Christopher Lundquist and Michael E. Staten (2007). "The Impact of Credit Counseling on Subsequent Borrow Behavior." The Journal of Consumer Affairs, Volume 41, Number 1, 1-28.

FSA (2001). Choosing a mortgage. Report of a research review and qualitative research on the mortgage buying process. London, UK.

FSA (2006). Financial Capability in the UK: Establishing a Baseline. London, UK.

Kamleitner, Bernadette and Erich Kirchler (2007). "Consumer Credit Use: A Process Model and Literature Review." European Review of Applied Psychology, Volume 57, Number 4, 267-283.

Lusardi, Annamaria (2008). "Financial Literacy: An Essential Tool for Informed Consumer Choice?". Working Paper Series, Joint Center for Housing Studies, Harvard University, Cambridge, Massachusetts, USA.

Lusardi, Annamaria and Olivia S. Mitchell (2007). "Financial Literacy and Retirement Preparedness: Evidence and Implications for Financial Education." Business Economics, Volume 42, Number 1, 35-44.

Martin, Matthew (2007). "A Literature Review on the Effectiveness of Financial Education.". Working Paper Series, Federal Reserve Bank of Richmond, Richmond, Virginia, USA.

Noctor, Michael, Sheila Stoney and Robert Stradling (1992). Financial Literacy: A Discussion of Concepts and Competences of Financial Literacy and Opportunities for its Introduction into Young People's Learning. National Foundation for Education Research, Slough, Berkshire, UK.

Peng, Tzu-Chin M., Suzanne Bartholomae, Jonathan J. Fox and Garrett Cravener (2007). "The Impact of Personal Finance Education Delivered in High School and College Courses." J Fam Econ Iss, Volume 28, Number 2, 265-284.

Ranyard, Rob, Lisa Hinkley, Janis Williamson and Sandie McHugh (2006). "The Role of Mental Accounting in Consumer Credit Decision Processes." Journal of Economic Psychology, Volume 27, Number 4, 571-588.

Worthington, Andrew C. (2004). "The Distribution of Financial Literacy in Australia.". Discussion Papers in Economics, Finance and International Competitiveness, Queensland University of Technology, Brisbane, QLD, Australia. 